Article

\title{
Enhancement of Plasticizing Effect on Bio-Based Polyurethane Acrylate Solid Polymer Electrolyte and Its Properties
}

\author{
Tuan Syarifah Rossyidah Tuan. Naiwi ${ }^{1}$, Min Min Aung ${ }^{1,2, *(\mathbb{0}, \text { Azizan Ahmad }}{ }^{3,4}$, \\ Marwah Rayung ${ }^{2}$, Mohd Sukor Su'ait ${ }^{4}$, Nor Azah Yusof ${ }^{1}$ and Khine Zar Wynn Lae ${ }^{5}$ \\ 1 Department of Chemistry, Faculty of Science, Universiti Putra Malaysia, UPM Serdang 43400, Selangor, Malaysia; \\ tnsyarifahrossyidah@gmail.com (T.S.R.T.N.); azahy@upm.edu.my (N.A.Y.) \\ 2 Higher Education Centre of Excellence (HiCoE), Institute of Tropical Forestry and Forest Products, \\ University Putra Malaysia, UPM Serdang 43400, Selangor, Malaysia; marwahrayung@yahoo.com \\ 3 School of Chemical Science and Food Technology, Faculty of Science and Technology, \\ Universiti Kebangsaan Malaysia, Bangi 43600, Selangor, Malaysia; azizan@ukm.edu.my \\ 4 Solar Energy Research Institute (SERI), Universiti Kebangsaan Malaysia, \\ UKM Bangi 43600, Selangor, Malaysia; mohdsukor@ukm.edu.my \\ 5 Department of Chemistry, Yangon University, Yangon11041, Myanmar; kzwlae@gmail.com \\ * Correspondence: minnminn_upm@gmail.com or minmin_aung@upm.edu.my
}

Received: 6 September 2018; Accepted: 9 October 2018; Published: 12 October 2018

check for updates

\begin{abstract}
Polyurethane acrylate (PUA) from vegetable oil has been synthesized and prepared for solid polymer electrolyte. Polyol has been end-capped with Toluene 2,4-Diisocyanate (TDI) followed by hydroxylethylmethylacrylate (HEMA) in a urethanation process to produce PUA. The mixtures were cured to make thin polymeric films under UV radiation to produce excellent cured films which exhibit good thermal stability and obtain high ionic conductivity value. 3 to $15 \mathrm{wt}$. \% of ethylene carbonate (EC) mixed with $25 \mathrm{wt}$. \% $\mathrm{LiClO}_{4}$ was added to PUA to obtain PUA electrolyte systems. PUA modified with plasticizer EC $9 \mathrm{wt}$. \% achieved the highest conductivity of $7.86 \times 10^{-4} \mathrm{~S} / \mathrm{cm}$, and relatively improved the linear sweep voltammetry, transference number and dielectric properties. Fourier Transform Infrared Spectroscopy (FTIR) and dielectric analysis were presented. Thermogravimetric analysis (TGA) and differential scanning calorimetry (DSC), followed by X-ray Diffraction (XRD) and morphology have been studied. The addition of plasticizer to the polyurethane acrylate shows significant improvement in terms of the conductivity and performance of the polymer electrolyte.
\end{abstract}

Keywords: biopolymer electrolyte; plasticizer; solid polymer; polyurethane acrylate; conductivity

\section{Introduction}

Polyurethane acrylate (PUA) is a copolymer that consists of urethane linkage (-NHCOO-) and the acrylate group in its molecular structure. It was synthesized from polyol and isocyanate with the addition of acrylate compound [1-5]. Commonly, PUA has been synthesized from polyether or polyester polyol of synthetic polymers as they have reactive sites to react with the isocyanate group. The properties of vegetable oil that can be modified to polyol have been studied to produce bio-based polymer PUA [6-10].

Urethane acrylate is mostly applicable for coating purposes with in situ polymerization via UV and is curable in the presence of reactive diluent and free radical photoinitiator. Urethane acrylate oligomer has been studied specifically for the UV curable polymer. Most of the studies on acrylate polymers are related to the UV radiation preparation method that have very high speeds of curing that lead to high productivity, lower energy consumption, reduction of volatile organic compound 
emission, reducing risk of fires, improving aspects of occupational safety and health and so forth [11,12]. Moreover, monomers derived from vegetable oil are environmentally friendly and low-cost compared to the synthetic polymer from petroleum.

The enhancement in ionic conductivity of polymer electrolyte can be achieved by the addition of either organic or inorganic filler into electrolyte systems such as $\mathrm{TiO}_{2}, \mathrm{SiO}_{2}, \mathrm{Al}_{2} \mathrm{O}_{3}$, ethylene carbonate (EC), and propylene carbonate. [13,14]. Inorganic filler promotes more free lithium ions and produces more amorphous regions in the electrolyte for the transfer of charge carriers. Meanwhile, organic filler acts as a plasticizer to reduce the glass transition temperature, $T_{g}$, of polymer, which helps to increase the segmental motion of the polymer backbone and generate free volume. Therefore, the ions can easily migrate through the void, resulting in a better ionic conductivity [15]. Plasticizers with high electric constant and low viscosity behavior enable them to be incorporated with a polymer host to facilitate the formation of dissociated ions [16]. Incorporation of a plasticizer into a polymer system is also a way to reduce crystallinity and increase the amorphous phase of a polymer electrolyte, thereby increasing the mobility of ions, and generating higher ionic conductivity [17]. The addition of EC increases the degree of salt dissociation and ionic mobility [18].

As the concentration of plasticizer increases, the amorphous nature of the electrolyte increases, thus improving the ionic conductivity of the polymer electrolyte. Plasticizers of poly(ethylene glycol) (PEG) with different molecular weight, $\mathrm{PEG}_{200}, \mathrm{PEG}_{400}$, and $\mathrm{PEG}_{600}$, showed that the conductivity of a polymer electrolyte decreases as molecular weight of plasticizer increases [19]. $\mathrm{PEG}_{200}$ has the largest concentration of free ions associated only with the anti-symmetric stretching mode in the matrix polymer. A longer chain length contributes to more oxygen, implying that lithium ions and few ions are available for ionic conduction, hence lower the ionic conductivity in the system. The smooth surface of the polymer electrolyte also observed for polymer with the highest conductivity in the present of EC. P(GMA-co-MMA) matrix has good flexibility of polymer chains with inclusion of EC and consequently improved the ionic conductivity [20].

In this research, biopolymer polyurethane acrylate electrolyte was synthesized from polyol of Jatropha oil in the presence of TDI and HEMA. The effect of plasticizing on conductivity and thermal stability of biopolymer electrolyte were studied. PUA modified with plasticizer EC $9 \%$ has the highest conductivity of $7.86 \times 10^{-4} \mathrm{~S} / \mathrm{cm}$ and the dielectric analysis was studied. The synthesized PUA was confirmed by Fourier Transform Infrared Spectroscopy (FTIR). The thermal behavior of the biopolymer electrolyte was studied by thermogravimetric analysis (TGA) and differential scanning calorimetry (DSC) and followed by X-ray Diffraction (XRD) and morphology study.

\section{Experimental}

\subsection{Material}

Jatropha oil was obtained from Biofuel Bionas, Kuala Lumpur, Malaysia and the oil was used as received. Hydrogen peroxide 30\% $\left(\mathrm{H}_{2} \mathrm{O}_{2}\right)$ and $\mathrm{N}, \mathrm{N}$-dimethylformamide (DMF) $(98 \%)$ were purchased form R\&M chemicals, Petaling Jaya, Malaysia. Formic acid (98\%) and tolulene 2,4-diisocyanate (TDI) (98\%) were purchased from Acros Organic, New Jersey, US). EC, 2-Hydroxyethylmethyl acrylate (HEMA) (99\%), 1,6-Hexanediol diacrylate (HDDA), 2-methylpropiopropanone (Darocure) and lithium perchlorate $\left(\mathrm{LiClO}_{4}\right)$ was obtained from Sigma Aldrich, St.Louis, Missouri, USA. All chemicals were used as received without further purification.

\subsection{Preparation of PUA Oligomer}

The PUA oligomer was prepared by reaction of the Jatropha oil-polyol with TDI in a four-necked round-bottom flask equipped with a mechanical stirrer, a thermometer, and a reflux condenser under nitrogen atmosphere. DMF was used as solvent. The TDI was added in a dropwise manner at $60^{\circ} \mathrm{C}$ and the reaction was continued for two hours to complete the NCO-terminated pre-polymer after confirmation by FTIR [21]. After that, the reaction was cooled down to $40{ }^{\circ} \mathrm{C}$ and HEMA was added 
in a dropwise manner. After complete adding of HEMA, the temperature was raised to $60{ }^{\circ} \mathrm{C}$ and the reaction was continuously stirred for one hour. From time to time, DMF was added to control the viscosity of the mixture since DMF solvent boiling point was high, as was control for usage [21]. In this study, the molar ratio of polyol to TDI and HEMA used is 1:1:1. The resulting PUA was transparent and yellowish in color.

\subsection{Preparation of PUA Film Electrolyte}

The PUA solid polymer electrolyte film was prepared by UV-curing and solution-casting method. Initially, the PUA was mixed together with HDDA (monomer) and Darocure (photoinitiator) for $3 \mathrm{~h}$. In separate flask, $25 \mathrm{wt}$. \% of lithium perchlorate salt and EC was dissolved in acetone for 12 h. The amount of EC used was varied from $0-15 \mathrm{wt}$. \% to find the optimum conductivity of the polymer electrolyte [21]. The two mixtures were then mixed together and stirred continuously for another $12 \mathrm{~h}$ to obtain a homogenous mixture. After that, the mixture was casted on a Teflon mold (diameter $100 \mathrm{~mm}$ ) and irradiated 3 times by a medium-pressure mercury vapor lamp from IST-UV Dryer (Switzerland) at $7.5 \mathrm{~mA}$ with the conveyor speed at $3 \mathrm{~m} / \mathrm{s}$. The solid film shows a uniform and transparent appearance as depicted in Scheme 1. The solid film was stored in a desiccator for one day to remove the residual solvent and undergo further characterization study. The samples were designated as PUA / 25 Li with 0 wt. \%, 3 wt. \%, 9 wt. \%, 12 wt. \% and 15 wt. \% EC in all characterizations.

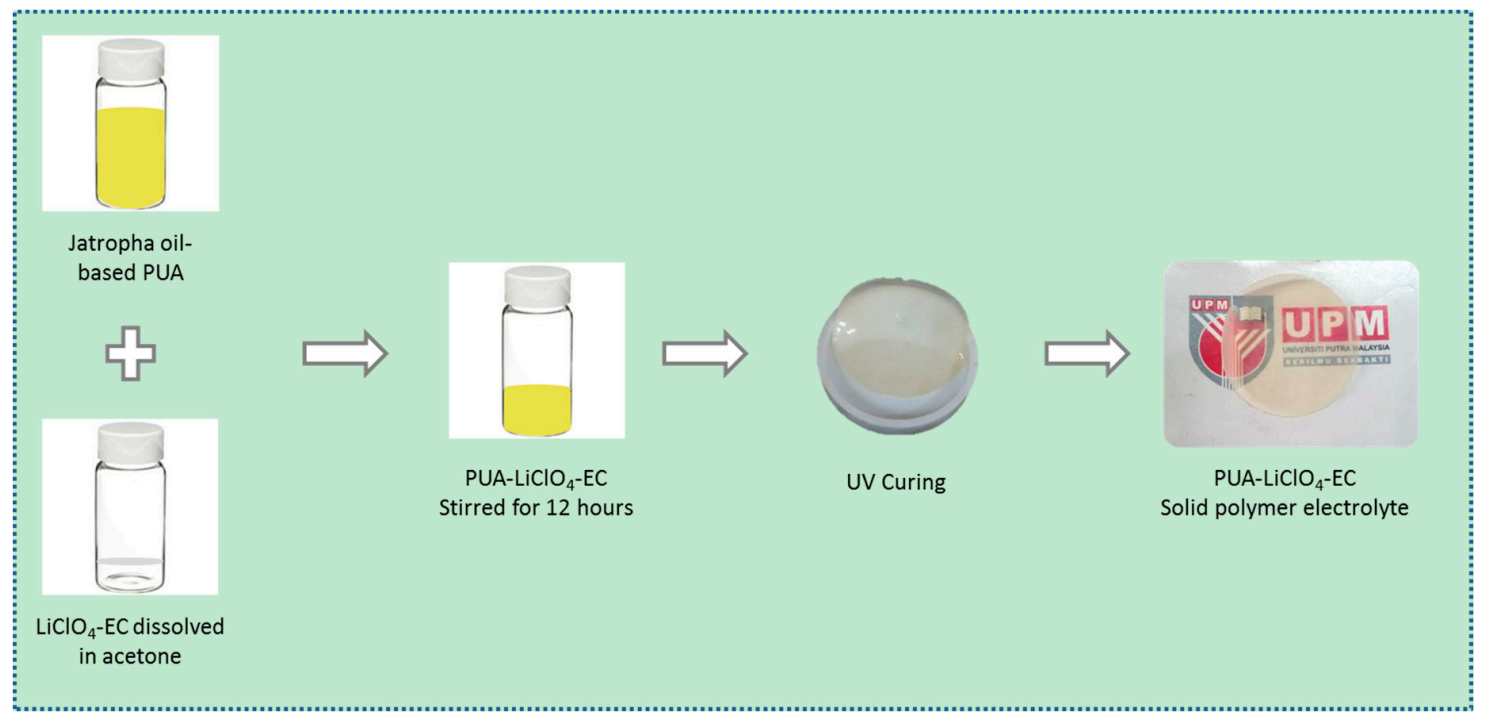

Scheme 1. The process of preparing solid polymer electrolyte from PUA and $\mathrm{LiClO}_{4}$ and EC.

\subsection{Characterization of Solid Polymer Electrolyte}

Infrared spectra were recorded with an ATR-FTIR, Perkin Elmer model 1650 (Waltham, US) in the wavenumber range between 4000 to $280 \mathrm{~cm}^{-1}$ with scanning resolution of $4 \mathrm{~cm}^{-1}$. TGA was performed using Mettler TA300 (Polaris Pkwy, Columbus Oh, US) from $50{ }^{\circ} \mathrm{C}$ to $600{ }^{\circ} \mathrm{C}$ with a heating rate of $10^{\circ} \mathrm{C} / \mathrm{min}$ in a dynamic nitrogen atmosphere at $20 \mathrm{~mL} / \mathrm{min}$ flow rate. Meanwhile, DSC Mettler TA300 was used to study the phase transition of the polymer electrolyte during the heating process. The study was conducted between $-50{ }^{\circ} \mathrm{C}$ (for $0 \% \mathrm{EC}$ ), $0{ }^{\circ} \mathrm{C}$ (with EC) to $150{ }^{\circ} \mathrm{C}$, at $10^{\circ} \mathrm{C}$ scanning rate under nitrogen atmosphere at $10 \mathrm{~mL} / \mathrm{min}$ flow rate. The structural information was studied by

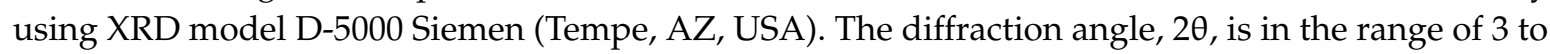
60 at $0.004 \%$ S. Scanning electron microscopy, SEM model JEOL JSM-7600F (Singapore) was used to investigate the surface morphology of the PUA electrolyte. Prior to analysis, the sample was coated with gold to avoid electrostatic charging. 


\section{Electrochemical Study}

The room-temperature ionic conductivity of the PUA SPE was studied by using Electrochemical Impedance Spectroscopy (EIS) using Hioki 3532-50 LCR Hi-tester (Nagano, Japan) that was interfaced to a computer in the frequency range of $50 \mathrm{~Hz}$ to $500 \mathrm{kHz}$. The film was cut into disc shapes with $16 \mathrm{~mm}$ diameter and $5.13 \mathrm{~cm}^{2}$ contact surface area. The film thickness was $0.05 \mathrm{~cm}$. The film was sandwiched between two stainless steel (SS) electrodes. The ionic conductivity, $\sigma$, was calculated based on the following equation:

$$
\sigma\left(\mathrm{S} \mathrm{cm}^{-1}\right)=\frac{l}{A \times R_{b}}
$$

where $l$ is the thickness of the film, $A$ is the area and $R_{b}$ is the bulk resistance obtained from the EIS measurement. The ratio which gave the highest conductivity will be subjected to temperature dependence study from room temperature, 303 to $383 \mathrm{~K}$.

The same ratio was used to study the electrochemical properties of the polymer electrolyte by using Linear Sweep Voltammetry (LSV) and Transference Number (TN) employing Princeton, Versa-STAT-4. For LSV, the sample was assembled in a symmetric SS/PE/Li configuration using $10 \mathrm{mV}$ scan rate in the range of 0-7 V. Sample preparations were carried out in the glove box with less than $0.1 \mathrm{ppm} \mathrm{H}_{2} \mathrm{O}$ and $\mathrm{O}_{2}$.

For TN measurement, the PUA electrolyte was assembled in a SS/PE/SS and polarized under a fixed direct current voltage with $0.1 \mathrm{~V}$. The value of $t_{i o n}$ was calculated from the current versus time plot by applying Wagner's polarization technique following the equation:

$$
\begin{gathered}
t_{\text {ion }}=\frac{I_{o}-I_{S S}}{I_{o}} \\
t_{\text {ele }}=\frac{I_{S S}}{I_{o}}
\end{gathered}
$$

where $t_{i o n}$ is ionic $\mathrm{TN}, t_{\text {ele }}$-electronic $\mathrm{TN}, I_{0}$-initial current, $I_{s S}$-the steady-state current.

The equations for dielectric constant $\left(\varepsilon_{r}\right)$, dielectric loss $\left(\varepsilon_{i}\right)$, real electrical modulus $\left(M_{r}\right)$, imaginary electrical modulus $\left(M_{i}\right)$ and $\tan \sigma$ were written as below:

$$
\begin{gathered}
\varepsilon_{r}=\frac{Z_{i}}{\omega C_{o}\left(Z_{r}^{2}+Z_{i}^{2}\right)} \\
\varepsilon_{i}=\frac{Z_{r}}{\omega C_{o}\left(Z_{r}^{2}+Z_{i}^{2}\right)} \\
M_{r}=\frac{\varepsilon_{r}}{\left(\varepsilon_{r}^{2}+\varepsilon_{i}^{2}\right)} \\
M_{i}=\frac{\varepsilon_{i}}{\left(\varepsilon_{r}^{2}+\varepsilon_{i}^{2}\right)} \\
\tan \delta=\frac{\varepsilon_{r}}{\varepsilon_{i}}
\end{gathered}
$$

where $C_{O}=\varepsilon_{O} A / t, \varepsilon_{O}=$ permittivity of free space and $\omega=2 \pi \mathrm{f}$.

\section{Results and Discussion}

The FTIR spectra of PUA with 25 wt. \% $\mathrm{LiClO}_{4}$ in different concentrations of EC are presented in Figure 1. The foremost interest in the PUA polymer electrolytes are region-free and hydrogen bonded -NH stretching mode $\left(3800-3100 \mathrm{~cm}^{-1}\right)$, oxygen atoms of the carbonyl $(\mathrm{C}=\mathrm{O})\left(1750-1710 \mathrm{~cm}^{-1}\right.$, $\left.1650 \mathrm{~cm}^{-1}\right)$, amine functional groups $(\mathrm{C}-\mathrm{N}$ and $\mathrm{N}-\mathrm{H})\left(1550-1500 \mathrm{~cm}^{-1}\right)$ and ether and ester group (C-O-C) (1300-1000 $\left.\mathrm{cm}^{-1}\right)$ stretch of acrylate group [22]. The carbonyl group of first band was electrostatically interacting within the polymer chain and with $\mathrm{Li}^{+}$ions, and the latter is interacting 
through H-bonds. The absorption peak of free and H-bonded -NH stretching of PUA have shifted $\left(3500 \mathrm{~cm}^{-1}\right.$ to $3700 \mathrm{~cm}^{-1}$ ) and showed an increase in the wavenumber when doping with lithium salt due to coordination of $\mathrm{Li}^{+}$ions to nitrogen atoms of the $-\mathrm{NH}$ groups. The peak between $1072-1173 \mathrm{~cm}^{-1}$ was assigned for the $\mathrm{C}-\mathrm{O}-\mathrm{C}$ stretching band for acrylate group. The urethane groups experienced a shift to a lower frequency $\left(1750 \mathrm{~cm}^{-1}\right.$ to $\left.1740 \mathrm{~cm}^{-1}\right)$. When adding salt, H-bonded C-O-C groups become free due to an interaction of $\mathrm{Li}^{+}$ions with the ether oxygen and its ability to form $\mathrm{H}$-bonds $[23,24]$. The PUA region interaction of lithium salt with an addition of $\mathrm{EC}$ in the region of oxygen atoms of the carbonyl $(\mathrm{C}=\mathrm{O})\left(1750-1710 \mathrm{~cm}^{-1}\right)$ and ether and ester group (C-O-C) $\left(1300-1000 \mathrm{~cm}^{-1}\right)$ stretch of acrylate group. The peak of polymer electrolyte shows no significant changes of wavenumber in the region of both carbonyl group and ester of stretch acrylate group upon addition of EC. However, an incorporation of $\mathrm{EC}$ into polymer electrolyte showed high intensity peak of $\mathrm{C}=\mathrm{O}$ carbonyl group of PUA. Thus, the plasticizer is essentially a filler dispersed in polymeric composite [16]. With addition of lithium salt the peaks shifted toward higher frequency and the peak of $\mathrm{C}=\mathrm{O}$ of PUA gave a high-intense, strong, and sharp peak at $1719-1712 \mathrm{~cm}^{-1}$. The addition of $25 \mathrm{wt}$. \% lithium shifted the intensity about $7 \mathrm{~cm}^{-1}$. This showed an interaction occurred between carbonyl group with lithium salt. The oxygen atoms act as electron donor atoms and form coordinate bonds with the lithium in the structure of polymer host. Thus, vibration frequency shifted to a lower wavenumber.

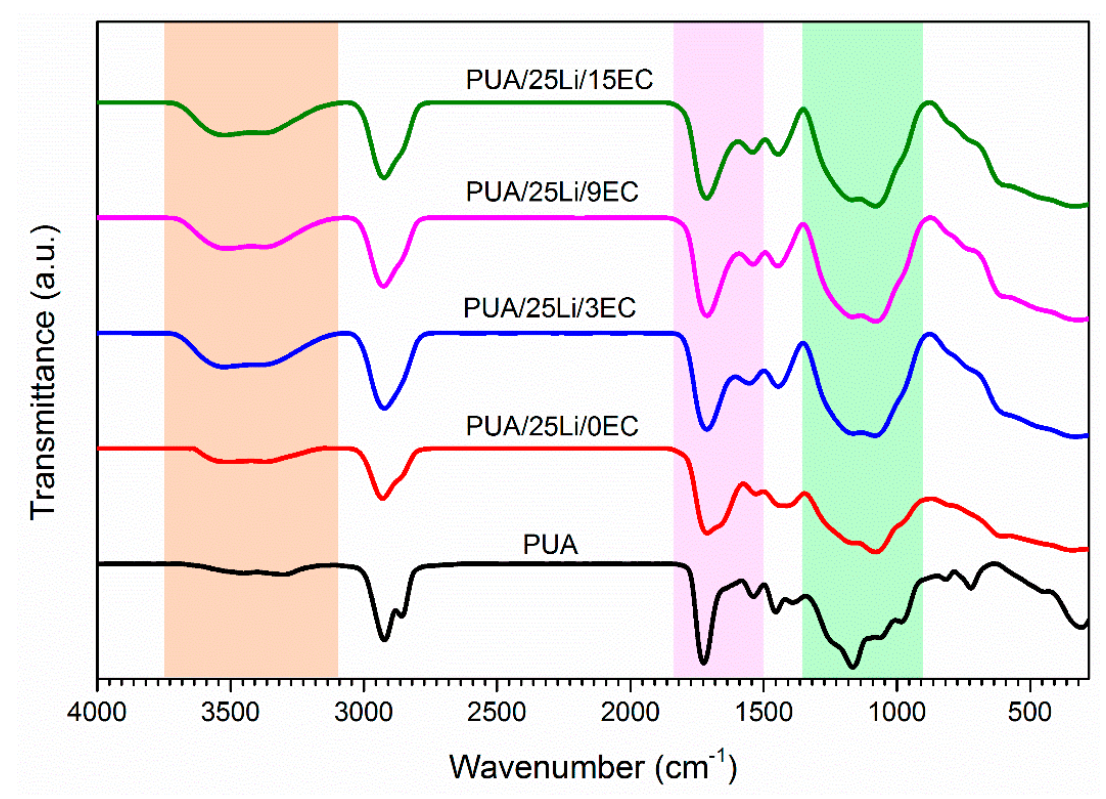

Figure 1. FT-IR spectra of PUA electrolyte at different loading of EC plasticizer.

The effect that plasticizing has on $\mathrm{PUA} / \mathrm{LiClO}_{4}$ polymer electrolyte is shown in Figure 2. The spectra shows the bulk resistance for $25 \mathrm{wt}$. \% EC at $\sim 10^{-4} \mathrm{ohm}$, decreasing to $\sim 10^{-5}$ at $25 \mathrm{wt}$. \% of EC. A graph of log conductivity versus concentration of EC added in Figure 3 shows the higher conductivity achieved with $9 \mathrm{wt}$. \% of EC and the value is illustrated in Table 1 . The addition of EC showed fluctuating value of conductivity and no apparent trend can be observed. However, the optimum conductivity $7.86 \times 10^{-4} \mathrm{~S} / \mathrm{cm}$ had achieved with $9 \mathrm{wt}$. $\%$ of EC, which was one order higher than $0 \mathrm{wt}$. \% EC. The conductivity decreased with addition of 3 to $6 \mathrm{wt}$. \% of EC then the conductivity increased and decreased again at $12 \mathrm{wt}$. \% of EC. EC acts as an organic plasticizer in the polymer electrolyte, enhancing the conductivity of the polymer electrolyte [20]. With the addition of $9 \mathrm{wt}$. \% EC, the conductivity improvement might be due to the high dielectric constant of the plasticizer, increasing the number of ions by weakening the columbic force between anion and cation salts. Therefore, dissociation of salts in the system increased and more free $\mathrm{Li}^{+}$ions can be produced [16]. More $\mathrm{Li}^{+}$ions and EC molecules can transfuse into the polymer matrix and increase the chain segmental mobility, leading to enhancement of conductivity. However, the conductivity 
starts to decrease, since its saturated level for EC results in less space for Li ions to move within the polymer matrix [20]. The ionic conductivity could be explained by interaction between polymer $\mathrm{LiClO}_{4}$ and EC. The main three interactions among them are ion-ion interaction between $\mathrm{Li}^{+}$cations and $\mathrm{ClO}_{4}$ - anions; ion-dipole interaction between $\mathrm{Li}^{+}$cations and chlorine in polymer; and ion-molecule interaction between $\mathrm{Li}^{+}$and EC. Polymer $\mathrm{LiClO}_{4}-\mathrm{EC}$ with different compounds of polymer $-\mathrm{Li}^{+}$, polymer $-\mathrm{Li}^{+} / \mathrm{EC}$ and $\mathrm{Li}^{+} / \mathrm{EC}$ exist by these interactions. The oxygen of $\mathrm{C}=\mathrm{O}$ in $\mathrm{EC}$ is an electron donor which participates in competition with $\mathrm{ClO}_{4}{ }^{-}$and polymer. The $\mathrm{Li}^{+} / \mathrm{EC}$ interaction exists not only between $\mathrm{Li}^{+}$and another two oxygen atoms of $\mathrm{C}=\mathrm{O}$ group, but also between $\mathrm{Li}^{+}$and another two oxygen atoms in the ring structure of EC. Moreover, $\mathrm{Li}^{+} / \mathrm{EC}$ interaction plays an important role in the conductivity of the polymer $\mathrm{LiClO}_{4}$-EC system. The addition of $\mathrm{EC}$ leads to the formation of a $\mathrm{Li}^{+} / \mathrm{EC}$ complex and enhances the flexibility of polymer chains by decreasing the crystalline fraction of the polymer $\mathrm{Li}^{+}$complex [25].

Table 1. Ionic conductivity of PUA electrolyte with EC plasticizer.

\begin{tabular}{cc}
\hline EC, wt. \% & Conductivity, $\boldsymbol{\sigma}\left(\mathbf{S ~ c m}^{-\mathbf{1}}\right)$ \\
\hline $0 \%$ & $6.40 \times 10^{-5}$ \\
$3 \%$ & $3.51 \times 10^{-6}$ \\
$6 \%$ & $7.05 \times 10^{-6}$ \\
$9 \%$ & $7.86 \times 10^{-4}$ \\
$12 \%$ & $7.59 \times 10^{-6}$ \\
$15 \%$ & $5.95 \times 10^{-6}$ \\
\hline
\end{tabular}

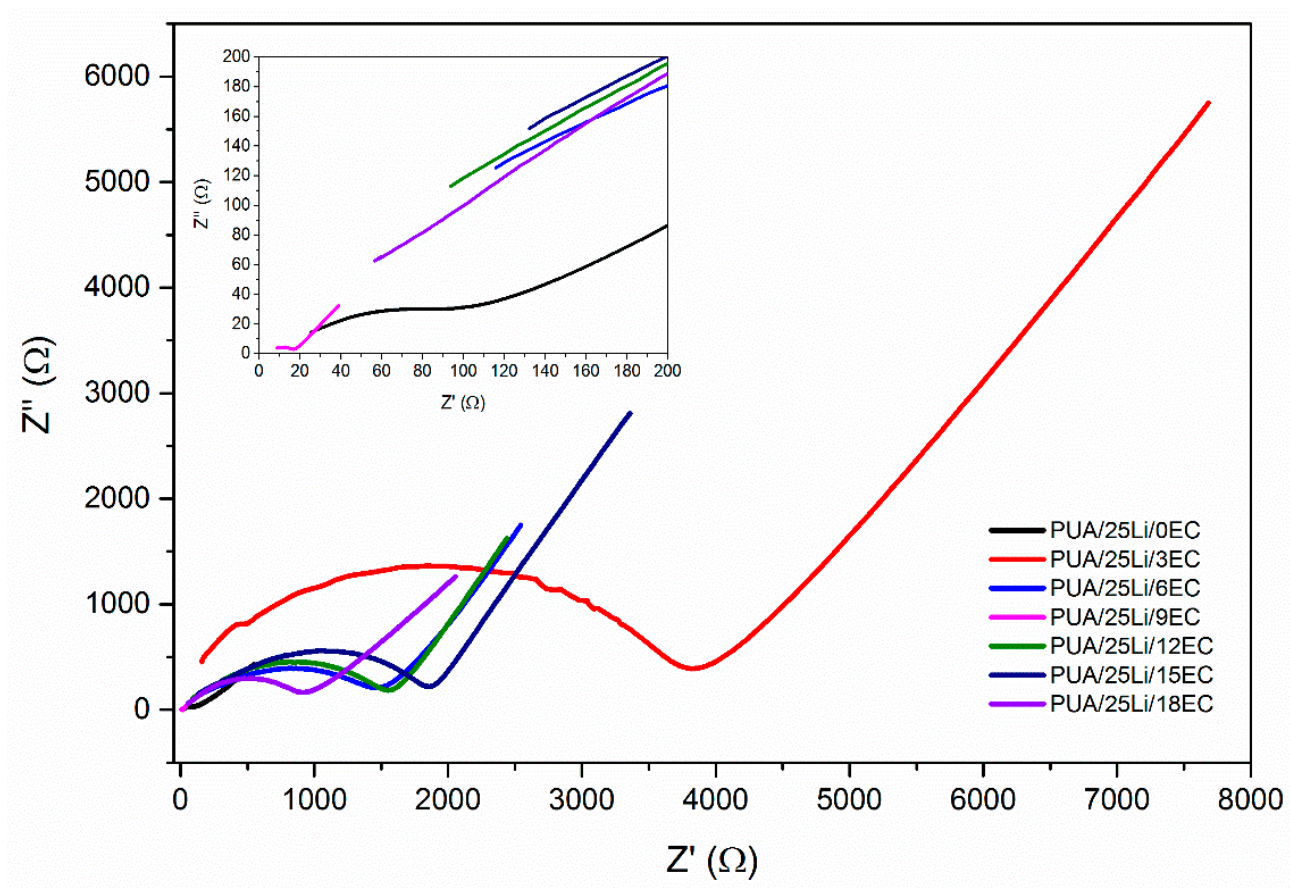

Figure 2. Nyquist plot of PUA electrolyte with EC plasticizer. 


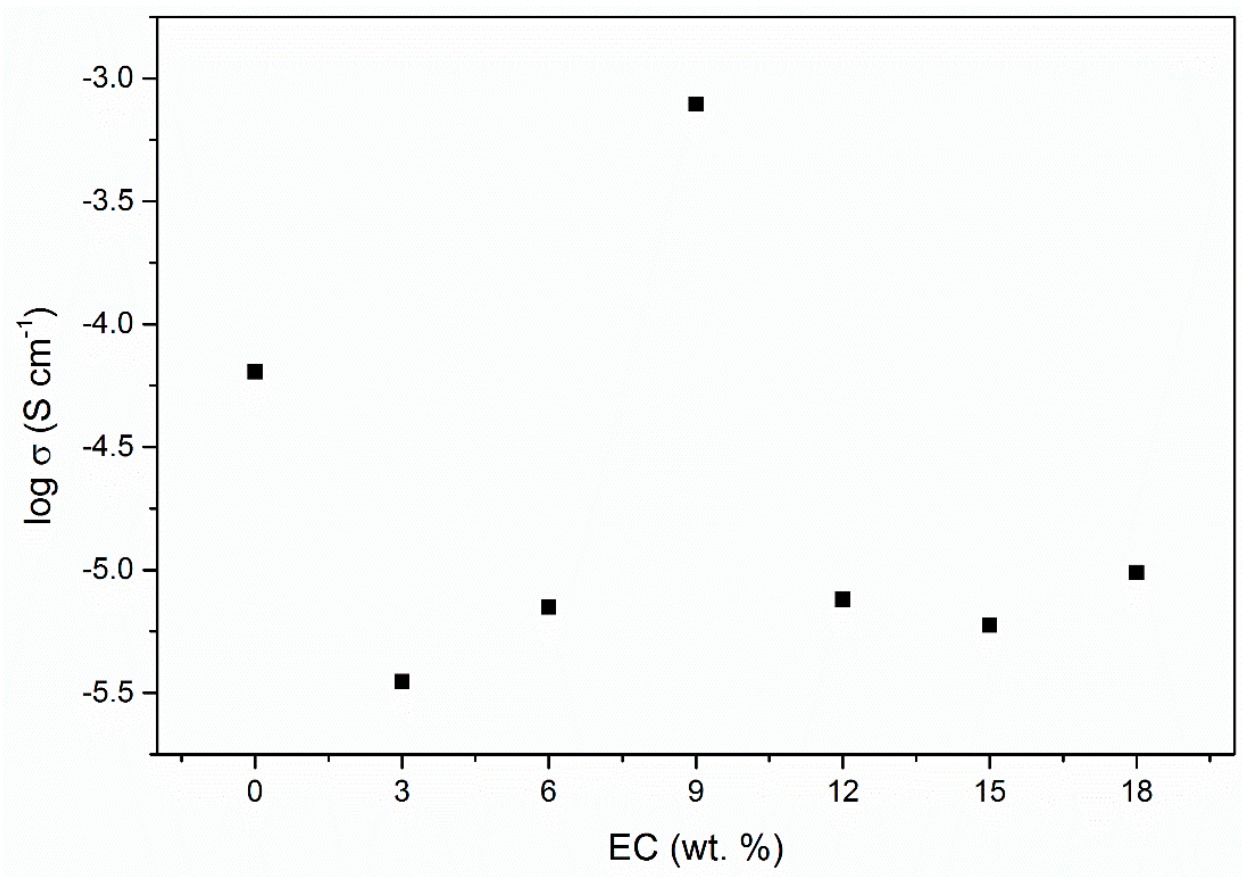

Figure 3. Log conductivity of PUA electrolyte at varied concentrations of EC plasticizer.

The conductivity of polymer electrolyte at ambient temperature to $100{ }^{\circ} \mathrm{C}$ was fitted using Arrhenius theory. The temperature dependence ionic conductivity was study to analyze mechanism of ion transportation in polymer electrolytes. The log $\sigma$ versus 1000/T grafted in Figure 4 showed linear plot well-fitted with Arrhenius theory as follows:

$$
\sigma=\mathrm{A}_{\exp }\left[E_{\mathrm{a}} / k T\right]
$$

where $\mathrm{A}$ is a constant which is proportional to the amount of charge carriers, $E_{\mathrm{a}}$ is activation energy, $k$ is Boltzmann constant and $T$ represents the absolute temperature in $\mathrm{K}$.

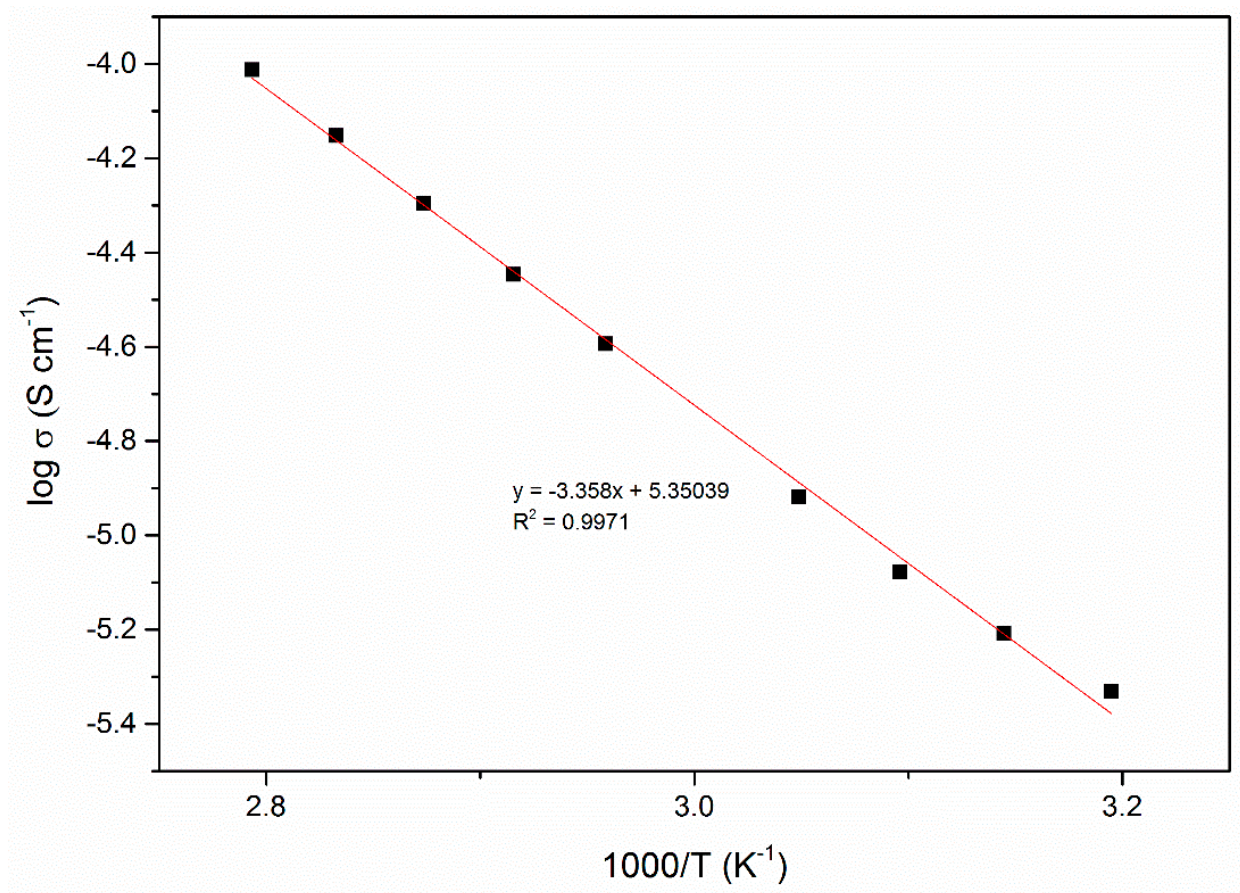

Figure 4. Arrhenius plot of ionic conductivity of $\mathrm{PUA} / \mathrm{LiClO}_{4} / \mathrm{EC}(9 \mathrm{wt}$ \%) electrolyte. 
The pseudo-activation energy, $E_{\mathrm{a}}$ of the polymer electrolyte was determined from the Arrhenius graph. $-E_{\mathrm{a}} / \mathrm{k}$ is denoted on the graph slope and the activation energy is $0.29 \mathrm{eV}$. The value of activation energy for is related to the ionic conductivity. The higher ionic conductivity only has lower activation energy and vice versa. This indicated that the higher conducting electrolyte requires only a smaller energy to start a migration process [22]. Based on reported study, the lower $E_{\mathrm{a}}$ provides a smaller band gap which allows the conducting ion to move more easily in a free ion-like state, hence increase ionic conductivity. This phenomenon also related to the conduction process, and lower $E_{\mathrm{a}}$ is required for the migration of ions in a highly conducting sample. Since migration of ions is tremendously affected by polymer segmental motion, an electrolyte with a lower $E_{\mathrm{a}}$ facilitates ionic movement, which then increases conductivity [23]. The DC current was observed as a function of time on application of a fixed voltage across SS/polymer electrolyte/SS cells. The normalized current versus time plots was shown in Figure 5 for PUA electrolyte with EC. Based on the plotted graph, the initial total current decreased with time due to depletion of ionic species in the electrolyte and becomes constant in the fully depleted situation. The cell was polarized and current flows when electrons migrate across the electrolyte and interface under a steady-state condition. This is because ionic currents through an ion-blocking electrode fall rapidly with time if the electrolyte is primarily ionic [24]. The value of TN for PUA electrolyte is 0.99 , and a PUA electrolyte with plasticizer is 0.95 , respectively. This clearly reveals that Li salt complexes with PUA and PUA electrolyte with EC becomes an almost perfect ionic conductor. The reported ionic TN of biopolymer electrolyte containing corn starch by Liew \& Ramesh (2013) [26] is 0.98 with ionic conductivity of $3.21 \times 10^{-4} \mathrm{~S} \mathrm{~cm}^{-1}$ accepted for a biopolymer electrolyte. The electrochemical stability window of polymer electrolyte was obtained by LSV technique. The sample was sandwiched between SS/PUA electrolyte/Li metal electrodes at ambient temperature. The potential was scanned between 1.0 to $5.0 \mathrm{~V}$ at a sweep rate of $5 \mathrm{mV} \mathrm{s}^{-1}$. The stability windows are increased from 1.6 to $4.1 \mathrm{~V}$ for PUA electrolyte with addition of $9 \mathrm{wt}$ \% EC as plasticizer, as shown in Figure 6. Based on the results, these PUA electrolytes are similar to those of Monisha (2016), which could be used for energy storage devices [27].

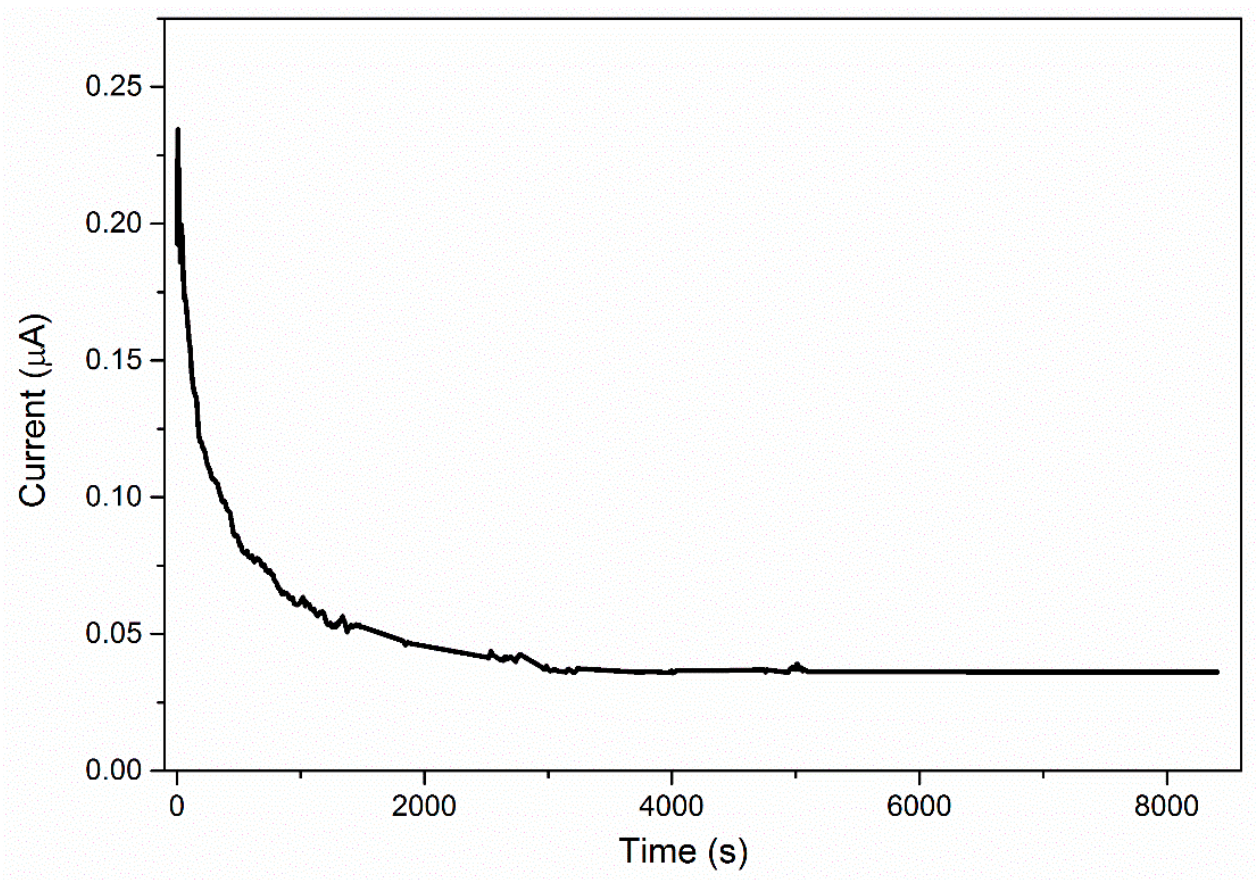

Figure 5. Normalized polarization current versus time for $\mathrm{PUA} / \mathrm{LiClO}_{4} / \mathrm{EC}(9 \mathrm{wt}$ \%) electrolyte. 


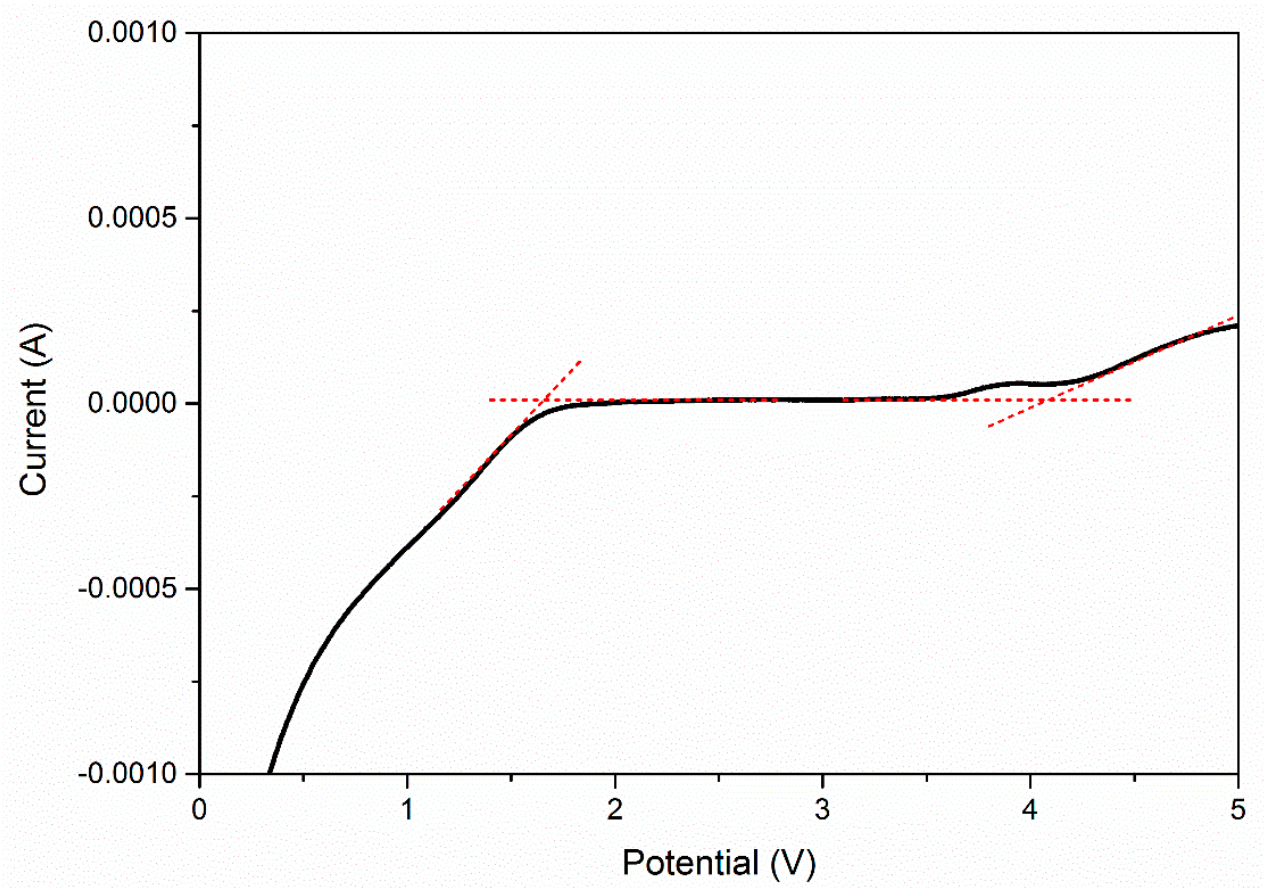

Figure 6. Linear Sweep Voltammetry of PUA/ $\mathrm{LiClO}_{4} / \mathrm{EC}$ (9 wt. \%) electrolyte.

In this research, EC was added as plasticizer to increase ionic conductivity, $\sigma$, in the PUA solid polymer electrolyte. This was because EC (small organic molecules) had high dielectric constant and low vapor pressure [1]. To prove that, $\log$ dielectric constant $\left(\log \varepsilon_{r}\right)$ and $\log$ dielectric $\operatorname{loss}\left(\log \varepsilon_{i}\right)$ versus log frequency for different percentages of EC plasticizer with fixed $\mathrm{Li}$ content $(25 \% \mathrm{Li}$ ) were plotted and shown in Figure 7. From the figure, it can be seen that $\log \varepsilon_{r}$ and $\log \varepsilon_{i}$ had higher values at low frequency of about $2 \mathrm{~Hz}$. This may be due to electrode polarization effect [28], while at high frequency, it was observed that $\log \varepsilon_{r}$ and $\log \varepsilon_{i}$ had lower values because of the periodic reversal of electric field occurring at high speed, and this caused the ions to have insufficient time to diffuse into the electric field [28]. Furthermore, with the addition of EC plasticizer, it will cause a large amount of charge carriers to localize along with mobile ions. Thus, it will help to improve the value of ionic conductivity [1]. Figure 8 presented the real electrical modulus $\left(M_{r}\right)$ and imaginary electrical modulus $\left(M_{i}\right)$ with $\log$ frequency for different ratio percentages of EC plasticizer added into the fixed Li content. Both $M_{r}$ and $M_{i}$ had a value of almost zero with a long tail when approaching high frequency. This happened because of the electrode polarization phenomena, which makes it an insignificant contribution [28]. The presence of the long tail at low frequency $(1.5 \mathrm{~Hz}$ to $4.5 \mathrm{~Hz})$ observed that there was a large capacitance associated with the electrodes [29]. Other than that, at high frequency, both $M_{r}$ and $M_{i}$ observed increased linearity. From Figure 8, it can be seen that $M_{r}$ peak was much higher than $M_{i}$ peaks. This was due to the samples of PUA solid polymer electrolyte being an ionic conductor [29]. Figure 6 compared the variation of tan $\sigma$ with log frequency for different additions of percentages of EC plasticizer into the Li content. From Figure 9, it can be seen that the tan $\sigma$ peaks were gradually shifted to $3.5 \mathrm{~Hz}$ to $5.0 \mathrm{~Hz}$ (higher frequency). With increase in EC plasticizer, it can help to increase the amorphous content in the PUA solid polymer electrolyte [27]. As the tan $\sigma$ peaks shifted toward the right-hand side, it will reduce the relaxation time $(\tau)$, which can be demonstrated from Table 2 . From Figure 9, PUA 25\% Li $+9 \%$ EC had the lowest $\tau$ which was $0.0955 \times 10^{-4} \mathrm{~s}$ with highest ionic conductivity up to $7.86 \times 10^{-4} \mathrm{~S} \mathrm{~cm}^{-1}$. 

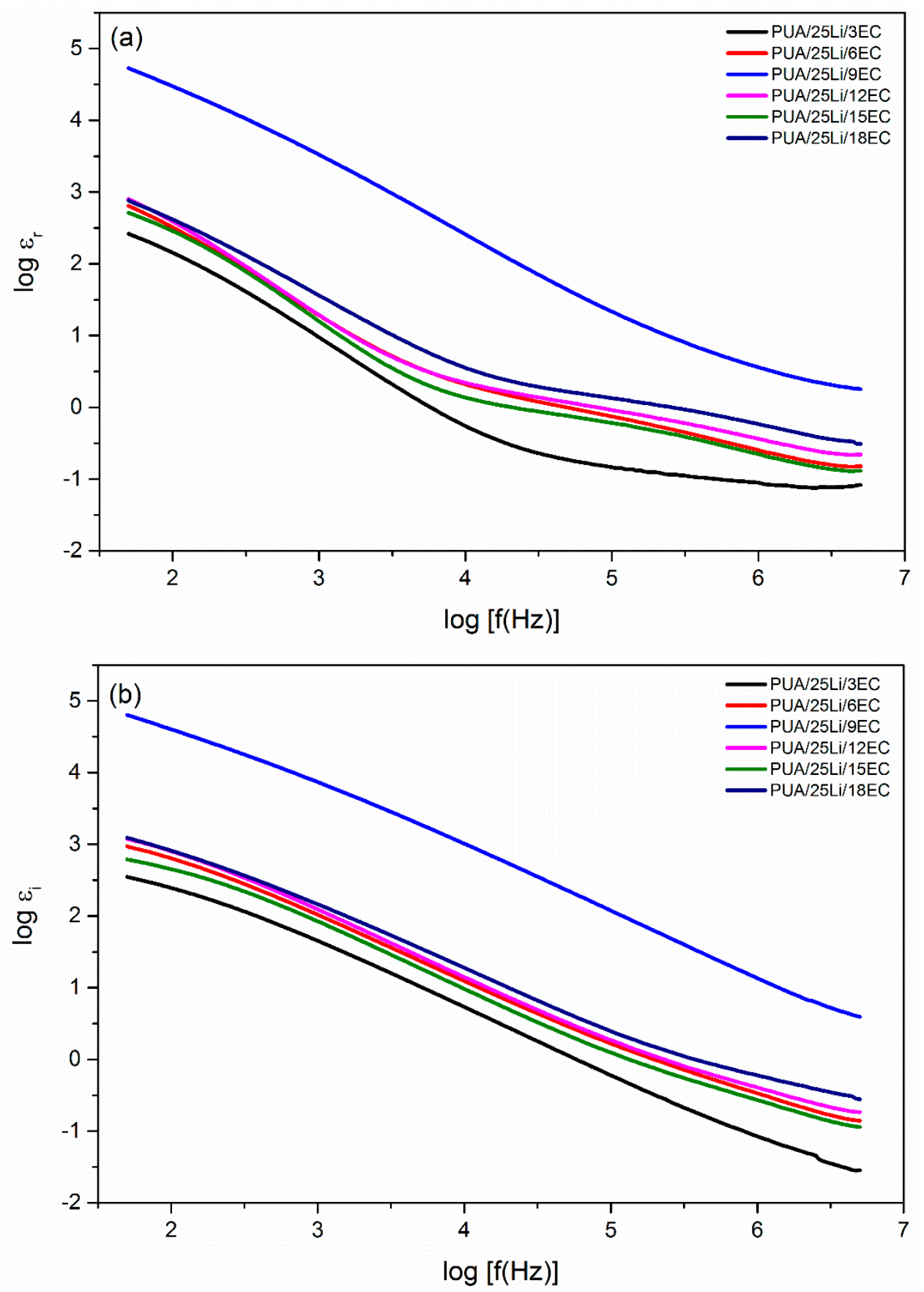

Figure 7. Variation of (a) $\log \varepsilon_{r}$ and (b) $\log \varepsilon_{i}$ versus $\log$ frequency $\mathrm{PUA} / \mathrm{LiClO}_{4} / \mathrm{EC}$ electrolytes. 

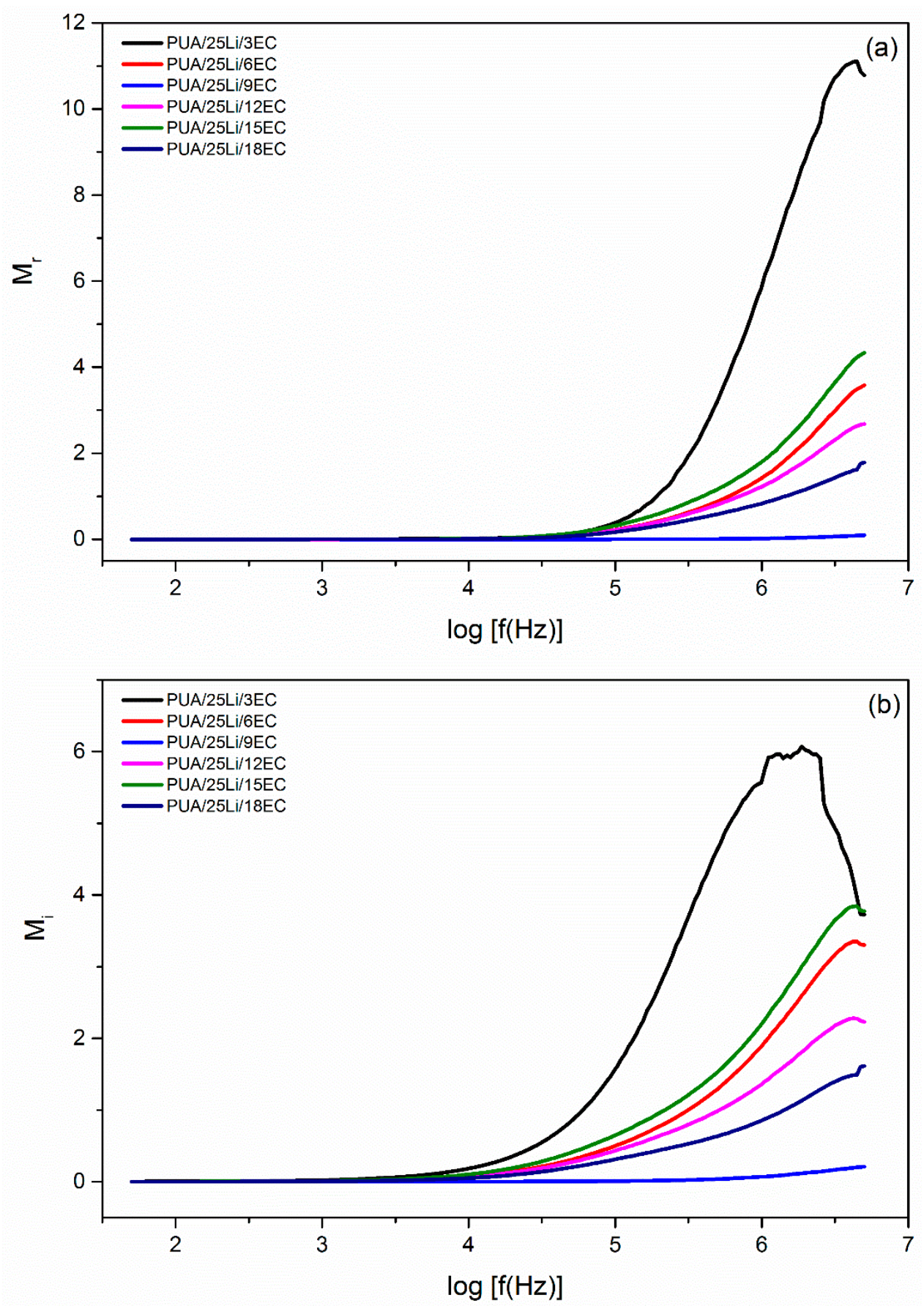

Figure 8. Variation of (a) real electrical modulus $\left(M_{r}\right)$ and $(\mathbf{b})$ imaginary electrical modulus $\left(M_{i}\right)$ of $\mathrm{PUA} / \mathrm{LiClO}_{4} / \mathrm{EC}$ electrolytes. 


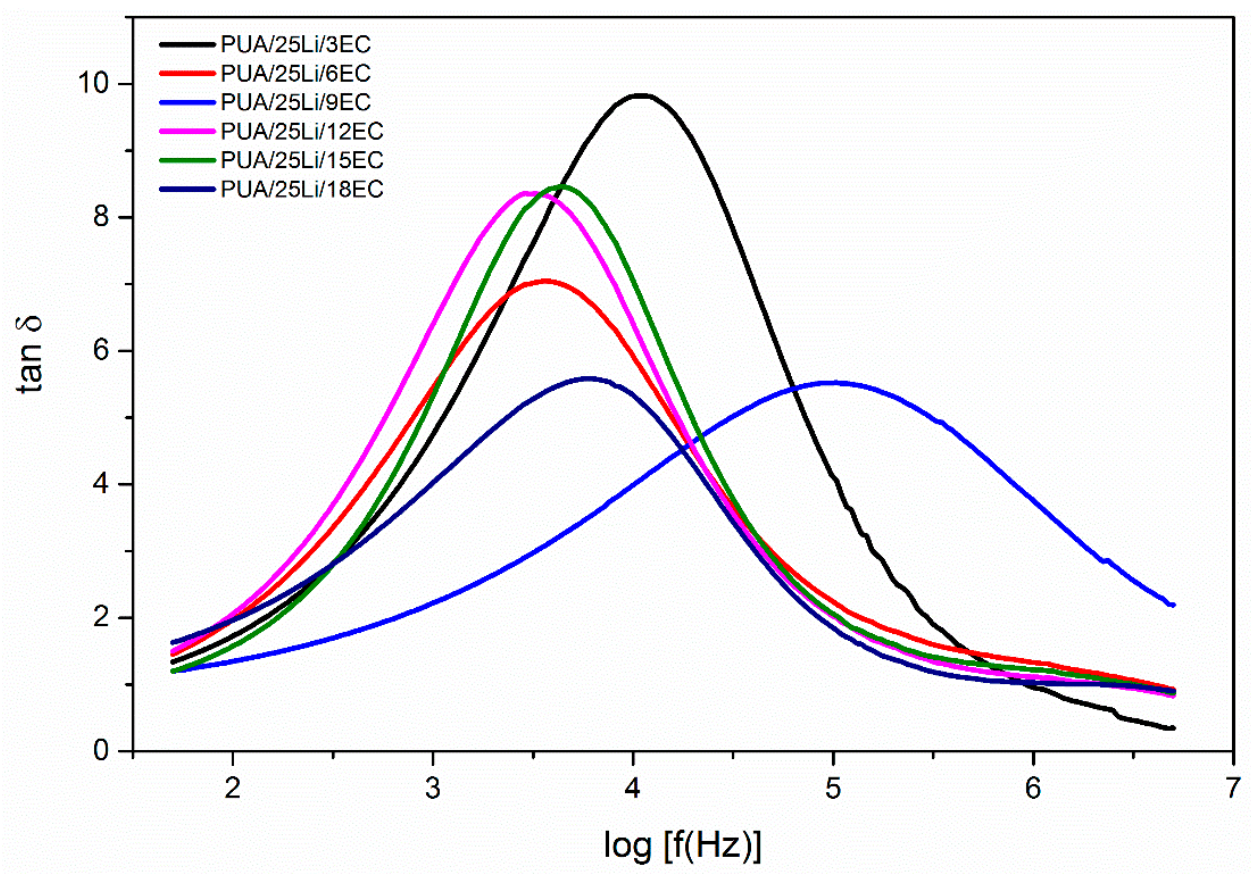

Figure 9. Variation of $\tan \sigma$ with $\log$ frequency at different percentage of EC plasticizer.

Table 2. Relaxation parameter for different ratio percentage of EC plasticizer.

\begin{tabular}{ccc}
\hline EC Content (\%) & Maximum Peak $(\mathbf{H z})$ & $\boldsymbol{\tau}\left(\times \mathbf{1 0}^{-\mathbf{4}} \mathbf{s}\right)$ \\
\hline 3 & 4.04 & 0.912 \\
6 & 3.56 & 2.75 \\
9 & 5.02 & 0.0955 \\
12 & 3.46 & 3.47 \\
15 & 3.61 & 2.45 \\
18 & 3.78 & 1.66 \\
\hline
\end{tabular}

TGA is the preferred technique for evaluation of the thermal stability of a polymer and indicates the decomposition of the polymer at various temperatures. From Figure 10a, the pure PUA has decomposed in three steps beginning at $53.4^{\circ} \mathrm{C}$ up to $186.8^{\circ} \mathrm{C}$, followed by a second stage at $199.7^{\circ} \mathrm{C}$ to $277.2^{\circ} \mathrm{C}$ with $\mathrm{T}_{\max } 253.8^{\circ} \mathrm{C}$. PUA had started to decompose at $53^{\circ} \mathrm{C}$ due to decomposition of solvent and moisture about $12.26 \mathrm{wt}$. \% mass loss [30]. There was still a small quantity of solvent degraded at second stage since the mass loss is about $7.43 \mathrm{wt}$ \%, which supports the decomposition of pure PUA at $278{ }^{\circ} \mathrm{C}$ with major loss $90 \mathrm{wt}$. \% whenever the pure polymer of PUA has decomposition at single step beginning, as reported by Digar et al. (2002), Santhosh et al. (2006) and Salih et al. (2014) [31-33]. From DTG, the major decomposition of PUA at $\mathrm{T}_{\max } 415.8^{\circ} \mathrm{C}$ was attributed to the decomposition of organic polymer chains, both the hard segment of urethane linkage and the soft segment from polyether or polyester. The analysis of TG and DTG thermograms was stated in Table 3. From DTG in Figure 10b, the temperature of maximum decomposition, $T_{\max }$, for ruptures of urethane linkage decreased upon increased concentration of the salt. The degradation of the PUA hard segment was $415{ }^{\circ} \mathrm{C}$ but decreased to $300{ }^{\circ} \mathrm{C}$ for PUA $25 \mathrm{wt}$. \% lithium salt. This phenomenon was suggested to be related to the low $\mathrm{T}_{\mathrm{g}}$ value of polymer electrolyte. The dipole-dipole interaction of polymer chains weakened when lithium salt was added, where it softens the backbone of the polymer chain and reduces the $T_{g}$ of the polymer. The same pattern result was obtained by Ugur et al., 2013 [34]. Based on Figure 10a,b, the decomposition of PUA electrolyte with EC was started at $50{ }^{\circ} \mathrm{C}$ due to the loss of moisture and solvent at the first stage of decomposition with $6-20 \%$ weight loss. There were three decomposition stages of polymer, as evaluated in Table 3. The major weight loss of polymer with $\mathrm{T}_{\max } 250-350{ }^{\circ} \mathrm{C}$ was decomposition of urethane linkage, as mention previously. As reported 
by Ramesh \& Ling, 2010 [35], the increase of plasticizer reduces the thermal stability of the polymer matrix. In this case, the polymers with EC have lower decomposition temperature compared to the without one.
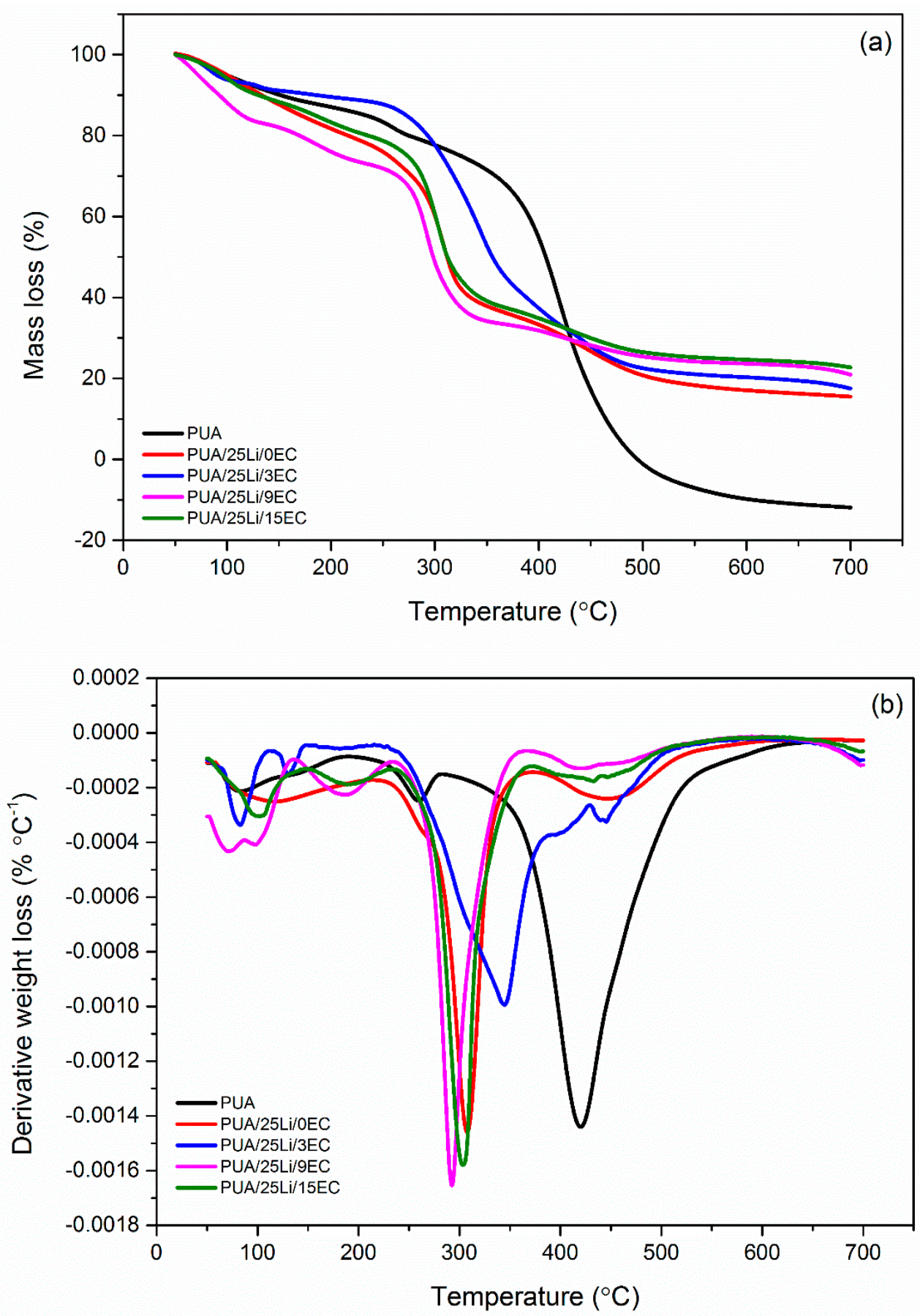

Figure 10. (a) TG and (b) DTG thermograms of neat PUA and PUA/ $\mathrm{LiClO}_{4} / \mathrm{EC}$ electrolytes. 
Table 3. Analysis of TG and DTG of PUA and PUA/ $\mathrm{LiClO}_{4} / \mathrm{EC}$ electrolytes.

\begin{tabular}{|c|c|c|c|c|c|c|}
\hline \multirow{2}{*}{ Composition } & \multirow{2}{*}{$\begin{array}{l}\text { Decomposition } \\
\text { Stage }\end{array}$} & Onset & Final & \multirow{2}{*}{$\begin{array}{c}\text { Temp of Max } \\
\text { Decomposition }\left({ }^{\circ} \mathrm{C}\right)\end{array}$} & \multirow{2}{*}{ Weight Loss (\%) } & \multirow[b]{2}{*}{ Residue (\%) } \\
\hline & & \multicolumn{2}{|c|}{$\begin{array}{c}\text { Degradation } \\
\text { Temp }\left({ }^{\circ} \mathrm{C}\right)\end{array}$} & & & \\
\hline \multirow{3}{*}{ PUA 0 wt. \% Li } & $\mathrm{d}_{1}$ & 53.38 & 186.75 & 79.43 & 12.26 & \multirow{3}{*}{0} \\
\hline & $\mathrm{d}_{2}$ & 199.67 & 277.18 & 253.75 & 7.43 & \\
\hline & $\mathrm{d}_{3}$ & 278.02 & 646.83 & 415.77 & 90.45 & \\
\hline \multirow{3}{*}{0 wt. $\%$ EC } & $\mathrm{d}_{1}$ & 55.98 & 208.62 & 107.07 & 19.62 & \multirow{3}{*}{17.34} \\
\hline & $\mathrm{d}_{2}$ & 209.87 & 371.83 & 304.55 & 44.59 & \\
\hline & $\mathrm{d}_{3}$ & 372.66 & 579.84 & 447.94 & 18.1 & \\
\hline \multirow{3}{*}{3 wt. \% EC } & $\mathrm{d}_{1}$ & 53.67 & 108.96 & 82.88 & 6.58 & \multirow{3}{*}{21.14} \\
\hline & $\mathrm{d}_{2}$ & 112.41 & 146.72 & 129.37 & 1.99 & \\
\hline & $\mathrm{d}_{3}$ & 215.72 & 544.02 & 345.07 & 67.93 & \\
\hline \multirow{4}{*}{9 wt. \% EC } & $\mathrm{d}_{1}$ & 52.12 & 132.48 & 97.77 & 16.92 & \multirow{4}{*}{23.76} \\
\hline & $\mathrm{d}_{2}$ & 134.24 & 233.3 & 185.55 & 9.94 & \\
\hline & $\mathrm{d}_{3}$ & 234.36 & 363.81 & 294.33 & 39.45 & \\
\hline & $\mathrm{d}_{4}$ & 368.36 & 585.98 & 424.8 & 9.57 & \\
\hline \multirow{4}{*}{15 wt. $\%$ EC } & $\mathrm{d}_{1}$ & 54.7 & 141.67 & 97.51 & 11.03 & \multirow{4}{*}{18.46} \\
\hline & $\mathrm{d}_{2}$ & 146.95 & 230.59 & 187.2 & 8.12 & \\
\hline & $\mathrm{d}_{3}$ & 234.49 & 368.37 & 305.06 & 42.57 & \\
\hline & $\mathrm{d}_{4}$ & 353.33 & 520.54 & 433.31 & 11.09 & \\
\hline
\end{tabular}

The thermal behavior of polymer electrolyte with difference concentration of EC was obtained by DSC thermogram at Figure 11 and illustrated in Table 4. Figure 11 showed that the PUA sample only exhibited the glass transition temperature measured at $-18.1^{\circ} \mathrm{C}$ showed similar result with Feng et al. (2012) [36]. Each samples of polymer electrolyte showed one $\mathrm{T}_{\mathrm{g}}$ with addition of $\mathrm{Li}$ salt. Digar et al. suggest three major types of interaction of polymer electrolyte. (1) interaction of the ether oxygen with the $\mathrm{Li}^{+}$ions, leading to the formation of transient crosslinks between the polyether chains via the $\mathrm{Li}^{+}$ions, which restricts the segmental motion; (2) interaction of urethane $-\mathrm{NH}$ and carbonyl groups with the $\mathrm{Li}^{+}$ions leading to inter or intra molecular crosslinking; and (3) mixed ether-urethane interactions with the $\mathrm{Li}^{+}$ions leading to phase mixing of the hard and soft segments. Oxygen present in the acrylate group may also coordinate with $\mathrm{Li}^{+}$ ions [16]. The interaction of $\mathrm{Li}^{+}$happened within ether oxygen and possibility of interaction with oxygen present in acrylate group increased the $T_{g}$ of hard segment. This suggests that addition of salt transforms PUA into amorphous.

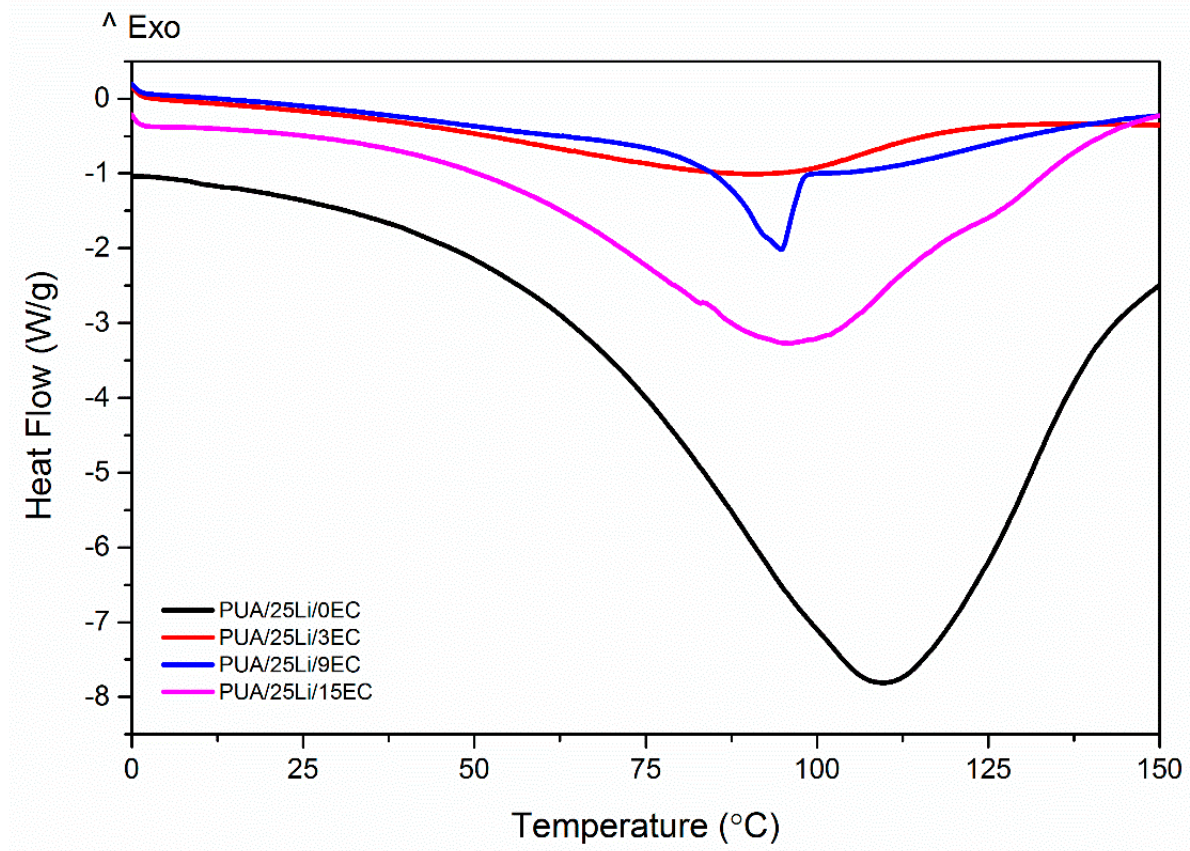

Figure 11. DSC thermograms $\mathrm{PUA} / \mathrm{LiClO}_{4} / \mathrm{EC}$ electrolytes. 
Table 4. Tm of PUA electrolyte with EC.

\begin{tabular}{cccc}
\hline Sample & $\begin{array}{c}\mathbf{T}_{\mathbf{m} 1} \\
\left({ }^{\circ} \mathbf{C}\right)\end{array}$ & $\mathbf{T}_{\mathbf{m} 2}\left({ }^{\circ} \mathbf{C}\right)$ & $\mathbf{T}_{\mathbf{g}}\left({ }^{\circ} \mathbf{C}\right)$ \\
\hline PUA 0 wt. \% EC & 108.9 & & -15.7 \\
PUA 3 wt. \% EC & 88.94 & & \\
PUA 9 wt. \% EC & 94.74 & 156.50 & \\
PUA 15 wt. \% EC & 95.89 & & \\
\hline \multicolumn{4}{l}{$\mathrm{T}_{\mathrm{m}}$-melting temperature; $\mathrm{T}_{\mathrm{g}}$-glass transition temperature. }
\end{tabular}

XRD analysis was carried out to study the crystallinity behavior of the polymer materials. Figure 12 shows the XRD pattern of PUA and PUA with EC electrolyte. The addition of EC to the PUA decreases the semi-crystalline phase by reducing the hump to a broad shape in the region between $15^{\circ}$ to $25^{\circ}$. By referring to the $\mathrm{XRD}$ pattern of $\mathrm{LiClO}_{4}$ as reported by [37], the semi-crystalline peaks are peaks of lithium salt. The lithium salt may be associated from the polymer matrix as shown in the SEM discussion, and agglomeration of polymer exists. PUA with EC has four broader humps of the amorphous region. The amorphous properties of polymer give significant reason for the increment of ionic conductivity, which might be due to the free volume created by continuous segmental motion of polymer chain. This helps ion migration and facilitates the movement of ions [38]. The amorphous nature of the polymer electrolyte was responsible for reducing $T_{g}$ value. It was shown that the more amorphous polymer had low $\mathrm{T}_{\mathrm{g}}$. This explains that the low $\mathrm{T}_{\mathrm{g}}$ in the amorphous phase had caused the polymer chains to produce faster bond rotations and segmental motion, hence giving better ionic mobility to the polymer electrolyte. The more amorphous region of polymer leads to a more disordered arrangement of the polymer matrix. Hence, the disorder induces more flexible polymer backbone then increases the mobility of charge carriers [20]. The PUA electrolyte with plasticizer shows good ionic conductivity.

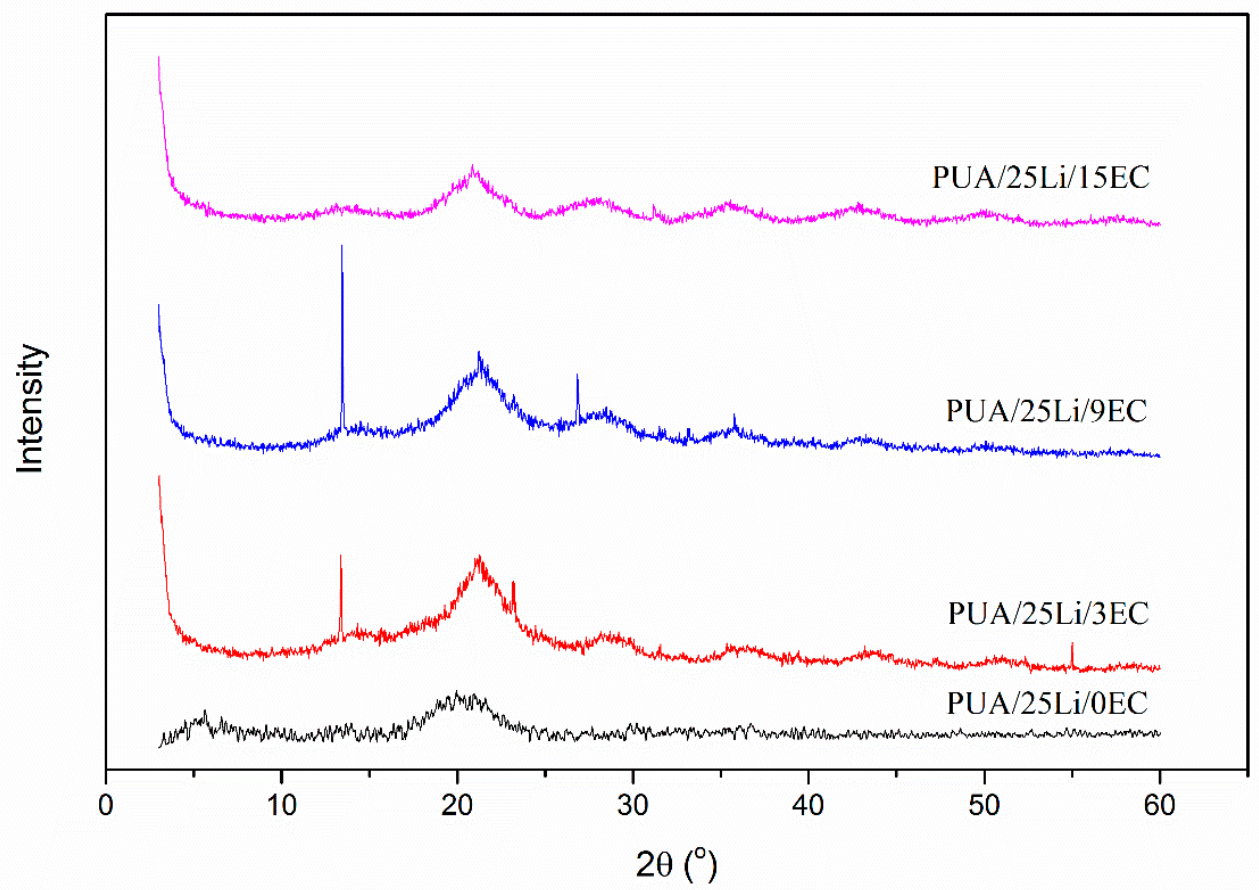

Figure 12. XRD pattern of $\mathrm{PUA} / \mathrm{LiClO}_{4}$ electrolyte at different EC concentrations.

The SEM micrograph for PUA electrolyte with EC $3 \mathrm{wt}$ \%, $9 \mathrm{wt}$. \% and $15 \mathrm{wt}$. \% is shown in Figure 13a-d. The surface morphology of PUA electrolyte is rough and porous surface. The surface roughness increased with addition of EC. Incorporation of EC with $3 \mathrm{wt}$. \% and $15 \mathrm{wt}$. \% have dark 
spot (porous structure) assumed phase separation occurred between EC and polymer matrix. Based on Ulaganathan et al. [37], this porosity leads to the entrapment of large volumes of liquid in the pores enhancing higher ionic conductivity. Pores present when the solvent evaporates then increase the amorphous region and solvent retention ability in the electrolyte system. The $9 \mathrm{wt}$. \% EC seems to be optimum for this system as Figure 13c shows smoothest surface morphology and no phase separation occurred. The smoother surface enhances the conductivity because the conducting ions will move freely in the electrolyte. The $9 \mathrm{wt}$ \% EC has higher conductivity due to increase of the ions in the polymer matrix [16]. Furthermore, the crystallinity of lithium salt presence leads to higher ionic conductivity. The spherical sizes relate to the lithium salt in the polymer matrix so that lithium does not dissolve completely on the polymer matrix. However, with the addition of $15 \mathrm{wt}$ \% EC, the dark spot and rough surface morphology resulted in low ionic conductivity compared to 9 wt. \% EC.
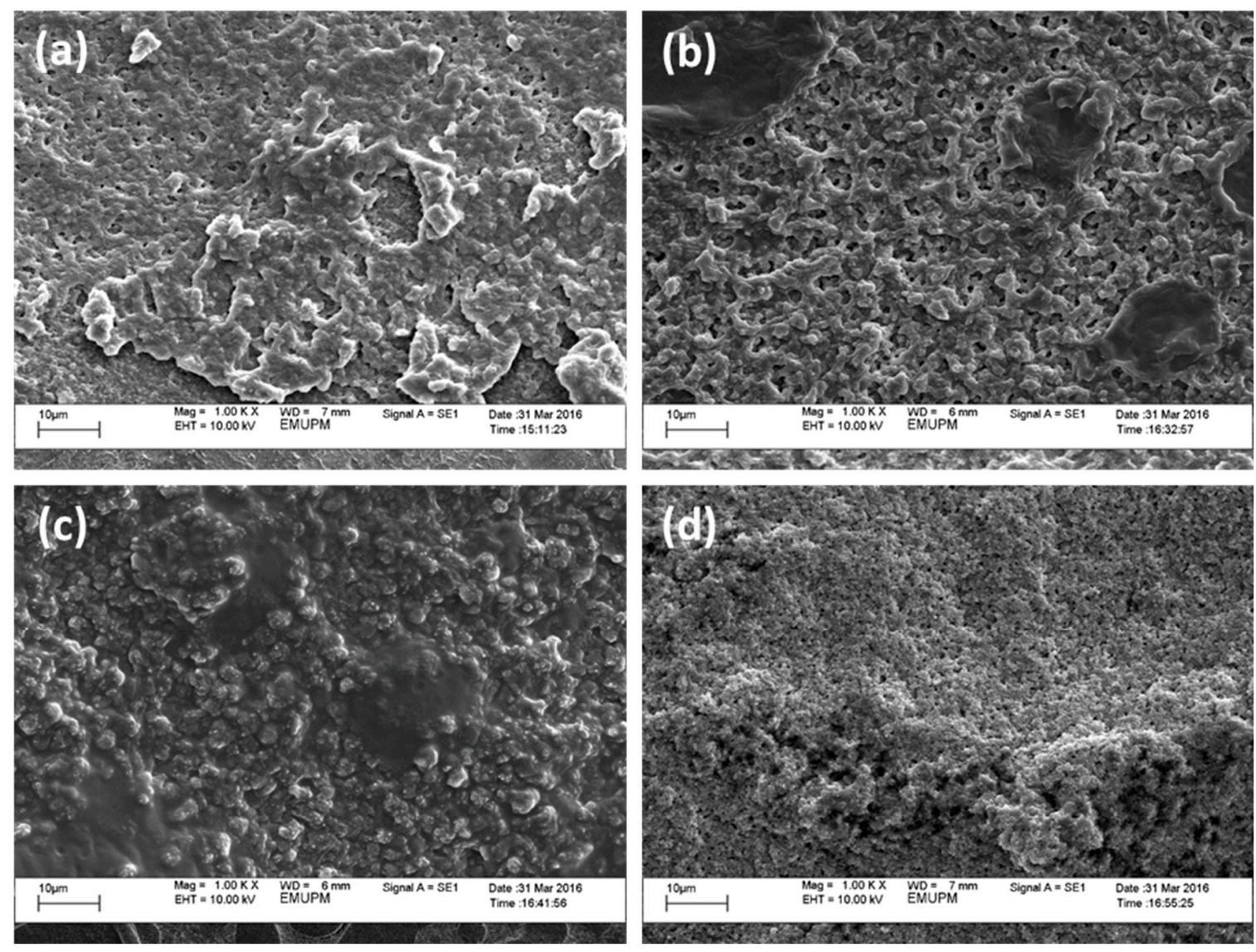

Figure 13. SEM micrograph $\mathrm{PUA} / \mathrm{LiClO}_{4} 25 \%$ electrolyte with $\mathrm{EC} \mathrm{(a)} 0 \%$ (b) $3 \%$ (c) $9 \%$ (d) $15 \%$.

\section{Conclusions}

The solid polymer electrolytes of PUA from polyol of Jatropha oil with different concentrations of EC have been successfully prepared by solution-casting method under UV irradiation technique. The highest conductivity of PUA electrolyte at room temperature was achieved approximately $\sim 7.86 \times 10^{-4} \mathrm{~S} / \mathrm{cm}$ at 9 wt. \% EC with $25 \mathrm{wt}$. \% $\mathrm{LiClO}_{4}$ which is increased by five magnitudes of order from the pure PUA. Interaction of lithium ions with oxygen atoms at ether group was shown in infrared spectra. Incorporation of EC into polymer electrolyte was shown in the high-intense of peak of the $\mathrm{C}=\mathrm{O}$ carbonyl group of PUA. Amorphous behavior of the polymer electrolyte can be observed by morphology study and was then confirmed by the thermal behavior of polymer electrolyte of TGA and DSC. XRD also showed the polymer electrolytes are amorphous in the presence of lithium salt by absence of crystallinity peak. Therefore, the ideal material for practical application with a wide range, battery and solar cell application could show potential useful application. 
Author Contributions: A.A., M.S.S., N.A.Y., M.M.A. and K.Z.W.L. designed the overall research. T.S.R.T.N. conducted the experiments. M.M.A., T.S.R.T.N. and M.R. wrote the manuscript. All authors reviewed the manuscript.

Acknowledgments: The authors acknowledge the Ministry of Science, Technology and Innovation for a grant of financial support (GP-IPB/9532000) University Putra Malaysia.

Conflicts of Interest: The authors declare no conflict of interest.

\section{References}

1. Pradhan, D.K.; Choudhary, R.N.P.; Samantaray, B.K. Studies of dielectric relaxation and AC conductivity behavior of plasticized polymer nanocomposite electrolytes. Int. J. Electrochem. Sci. 2008, 3, 597-608.

2. Huang, J.; Sun, J.; Zhang, R.; Zou, R.; Yuan, T. Improvement of biodegradability of UV-curable adhesives modified by a novel polyurethane acrylate. Prog. Organ. Coat. 2016, 95, 20-25. [CrossRef]

3. Zuber, M.; Shah, S.A.A.; Jamil, T.; Asghar, M.I. Performance behaviour of modified cellulosic fabrics using polyurethane acrylate copolymer. Int. J. Biol. Macromol. 2014, 67, 254-259. [CrossRef] [PubMed]

4. Wang, Y.; Qiu, F.; Xu, B.; Xu, J.; Li, P. Preparation, mechanical properties and surface morphologies of waterborn fluorinated polyurethane acrylate. Prog. Organ. Coat. 2013, 76, 876-883. [CrossRef]

5. Yaobin, R.; Huiming, P.; Longsi, L.; Jianming, X.; Yongqiang, Y. Synthesis of poylurethane acrylate and application to UV-curable pressure-sensitive adhesive. Des. Monomers Polym. 2005, 8, 383-396.

6. Hu, Y.; Shang, Q.; Tang, J.; Wang, C.; Zhou, Y. Use of cardanol-based acrylate as reactive diluent in UV -curable castor oil-based polyurethane acrylate resin. Ind. Crops Prod. 2018, 117, 295-302. [CrossRef]

7. Liu, B.; Nie, J.; He, Y. From rosin to high adhesive polyurethane acrylate: Synthesis and properties. Int. J. Adhes. Adhes. 2016, 66, 99-103. [CrossRef]

8. Chen, G.; Guan, X.; Xu, R.; Tian, J.; Yang, J. Synthesis and characterization of UV curable castor oil-based polyfunctional polyurethane acrylate via photo-click chemistry and isocyanate polyurethane reaction. Prog. Organ. Coat. 2016, 93, 11-16. [CrossRef]

9. Li, K.; Shen, Y.; Fei, G.; Wang, H.; Li, J. Preparation and properties of castor oil/ pentaerythritol triacrylate-baed UV curable waterborne poylurethane acrylate. Prog. Organ. Coat. 2015, 78, 146-154. [CrossRef]

10. Deepak, M.P.; Ganesh, A.P.; Mhaske, S.T. Design and synthesis of bio-based UV curable PU acrylate resin from itaconic acid for coating applications. Des. Monomers Polym. 2017, 20, 269-282.

11. Barbeau, P.H.; Gerard, J.F.; Magny, B.; Pascault, J.P. Effect of the diisocyanate on the structure and properties of polyurethane acrylate prepolymers. J. Polym. Sci. 2000, 38, 2750-2768. [CrossRef]

12. Asif, A.; Huang, C.; Shi, W. Structure-property study of waterborne, polyurethane acrylate dispersions based on hyperbranched aliphatic polyester for UV-curable coatings. Colloid Polym. Sci. 2004, 283, 200-208. [CrossRef]

13. Yap, Y.L.; You, A.H.; Teo, L.L.; Hanapei, H. Inorganic filler sizes effect on ionic conductivity in polyethylene (PEO) composite polymer electrolyte. Int. J. Electrochem. Sci. 2013, 8, 2154-2163.

14. Wang, W.; Yi, E.; Anthony, J.F.; Richard, M.L.; John, K. Lithium ion conducting poly ethylene oxide based solid electrolyte containing active or passive ceramic nanoparticles. J. Phys. Chem. 2017, 121, 2563-2573. [CrossRef]

15. Long, L.; Wang, S.; Xiao, M.; Meng, Y. Polymer electrolytes for lithium polymer batteries. J. Mater. Chem. A 2016, 4, 10038-10069. [CrossRef]

16. Low, S.P.; Ahmad, A.; Rahman, M.Y.A. Effect of ethylene carbonate plasticizer and $\mathrm{TiO}_{2}$ nanoparticles on $49 \%$ poly(methyl methacrylate) grafted natural rubber-based polymer electrolyte. Ionics 2010, 16, 821-826. [CrossRef]

17. Pitawala, H.M.J.C.; Dissanayake, M.A.K.L.; Seneviratne, V.A.; Mellander, B.E.; Albinson, I. Effect of plasticizers (EC or PC) on the ionic conductivity and thermal properties of the (PEO)(9) LiTf: $\mathrm{Al}_{2} \mathrm{O}_{3}$ nanocomposite polymer electrolyte system. J. Solid State Electrochem. 2008, 12, 783-789. [CrossRef]

18. Navaratnam, S.; Ramesh, K.; Ramesh, S.; Sanusi, A.; Basirun, W.J.; Arof, A.K. Transport mechanism studies of chitosan electrolyte systems. Electrochim. Acta 2015, 175, 68-73. [CrossRef]

19. Subban, R.H.Y.; Ahmad, A.H.; Kamarulzaman, N.; Ali, A.M.M. Effects of plasticiser on the lithium ionic conductivity of polymer electrolyte $\mathrm{PVC}-\mathrm{LiCF}_{3} \mathrm{SO}_{3}$. Ionics 2005, 11, 442-445. [CrossRef] 
20. Imperiyka, M.; Ahmad, A.; Hanifah, S.A.; Rahman, M.Y.A. Preparation and Characterization of Polymer Electrolyte of with Ethylene Carbonate. Int. J. Polym. Sci. 2014, 2014, 638279. [CrossRef]

21. Tuan Naiwi, T.S.R.; Aung, M.M. Effect of Lithium salt concentration on biopolymer polyurethane acrylate (PUA) of Jatorpha Oil electrolyte. In Proceedings of the International Symposium on advanced polymeric materials (ISAPM 2016), Kuala Lumpur, Malaysia, 16-18 May 2016.

22. Ibrahim, S.; Ahmad, A.; Mohamed, N.S. Characterization of novel castor oil-based polyurethane polymer electrolytes. Polymers 2015, 7, 747-759. [CrossRef]

23. Rani, M.S.A.; Rudhziah, S.; Ahmad, A.; Mohamed, N.S. Biopolymer electrolyte based on derivatives of cellulose from kenaf bast fiber. Polymers 2014, 6, 2371-2385. [CrossRef]

24. Samsudin, A.S.; Lai, H.M.; Isa, M.I.N. Biopolymer materials based carboxymethyl cellulose as a proton conducting biopolymer electrolyte for application in rechargeable proton battery. Electrochim. Acta 2014, 129, 1-13. [CrossRef]

25. Imperiyka, M.; Ahmad, A.; Hanifah, S.A.; Bella, F. A UV-prepared linear polymer electrolyte membrane for dye-sensitized solar cells. Phys. B 2014, 450, 151-154. [CrossRef]

26. Liew, C.W.; Ng, H.M.; Numan, A.; Ramesh, S. Poly(acrylic acid)-based hybrid inorganic-organic electrolytes membrane for electrical double layer capacitors application. Polymers 2016, 8, 179. [CrossRef]

27. Monisha, S.; Mathavan, T.; Selvasekarapandian, S.; Benial, A.M.F.; Latha, M.P. Preparation and characterization of cellulose acetate and lithium nitrate for advanced electrochemical devices. Ionics 2017, 23, 2697-2706. [CrossRef]

28. Ramesh, S.; Arof, A.K. Ionic conductivity studies of plasticized poly(vinyl chloride) polymer electrolytes. Mater. Sci. Eng. B Solid-State Mater. Adv. Technol. 2001, 85, 11-15. [CrossRef]

29. Khiar, A.S.A.; Puteh, R.; Arof, A.K. Conductivity studies of a chitosan-based polymer electrolyte. Phys. B Condens. Matter. 2006, 373, 23-27. [CrossRef]

30. Su'ait, M.S.; Ahmad, A.; Badri, K.H.; Mohamed, N.S.; Rahman, M.Y.A.; Ricardo, C.L.A.; Scardi, P. The potential of polyurethane bio-based solid polymer electrolyte for photoelectrochemical cell application. Int. J. Hydrog. Energy 2014, 39, 3005-3017. [CrossRef]

31. Digar, M.; Hung, S.L.; Wang, H.L.; Wen, T.C.; Gopalan, A. Study of ionic conductivity and microstructure of a cross-linked polyurethane acrylate electrolyte. Polymer 2002, 43, 681-691. [CrossRef]

32. Santhosh, P.; Vasudevan, T.; Gopalan, A.; Lee, K. Preparation and properties of new cross-linked polyurethane acrylate electrolytes for lithium batteries. J. Power Sources 2006, 160, 609-620. [CrossRef]

33. Salih, A.M.; Ahmad, M.B.; Ibrahim, N.A.; Dahlan, K.Z.; Tajau, R.; Mahmood, M.H.; Yunus, W.M.Z.W. Synthesis of radiation curable palm oil-based epoxy acrylate: NMR and FTIR spectroscopic investigations. Molecules 2015, 20, 14191-14211. [CrossRef] [PubMed]

34. Ugur, M.; Kilic, H.; Berkem, M.; Gungor, A. Synthesis by UV-curing and characterization of polyurethane acrylate-lithium salts-based polymer electrolytes in lithium batteries. Chem. Pap. 2014, 68, 1561-1572. [CrossRef]

35. Ramesh, S.; Ling, O.P. Effect of ethylene carbonate on the ionic conduction in poly(vinylidenefluoridehexafluoropropylene) based solid polymer electrolytes. Polym. Chem. 2010, 1, 702-707. [CrossRef]

36. Liao, F.; Zeng, X.; Li, H.; Lai, X.; Zhao, F. Synthesis and properties of UV curable polyurethane acrylates based on two different hydroxyethyl acrylates. J. Cent. South Univ. 2012, 19, 911-917. [CrossRef]

37. Ulaganathan, M.; Nithya, R.; Rajendran, S. Surface analysis studies on polymer electrolyte membranes using scanning electron microscope and atomic force microscope. Scanning Electron Microsc. 2012, 671-694. [CrossRef]

38. Johan, M.R.; Shy, O.H.; Ibrahim, S.; Mohd Yassin, S.M.; Hui, T.Y. Effects of $\mathrm{Al}_{2} \mathrm{O}_{3}$ nanofiller and EC plasticizer on the ionic conductivity enhancement of solid $\mathrm{PEO}-\mathrm{LiCF}_{3} \mathrm{SO}_{3}$ solid polymer electrolyte. Solid State Ionics 2011, 196, 41-47. [CrossRef]

(C) 2018 by the authors. Licensee MDPI, Basel, Switzerland. This article is an open access article distributed under the terms and conditions of the Creative Commons Attribution (CC BY) license (http://creativecommons.org/licenses/by/4.0/). 